\section{Underwater endoscopic mucosal resection of a large depressed adenoma in the ileum}

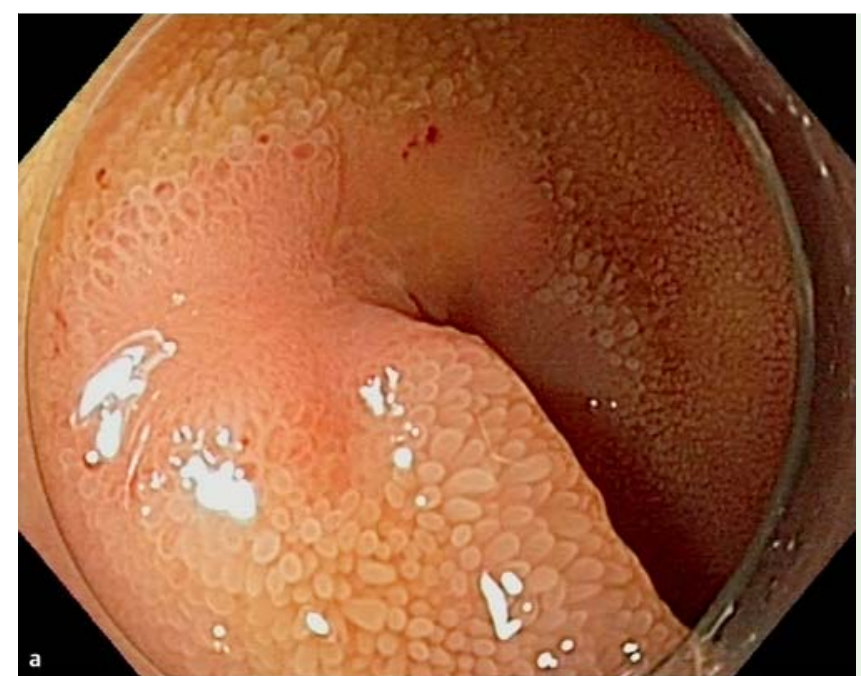

Fig. 1 Endoscopic photograph showing a large $(2.5 \mathrm{~cm})$ flat polyp with central scarring in the ileum. a White-light endoscopy. b Chromoendoscopy (indigo carmine).
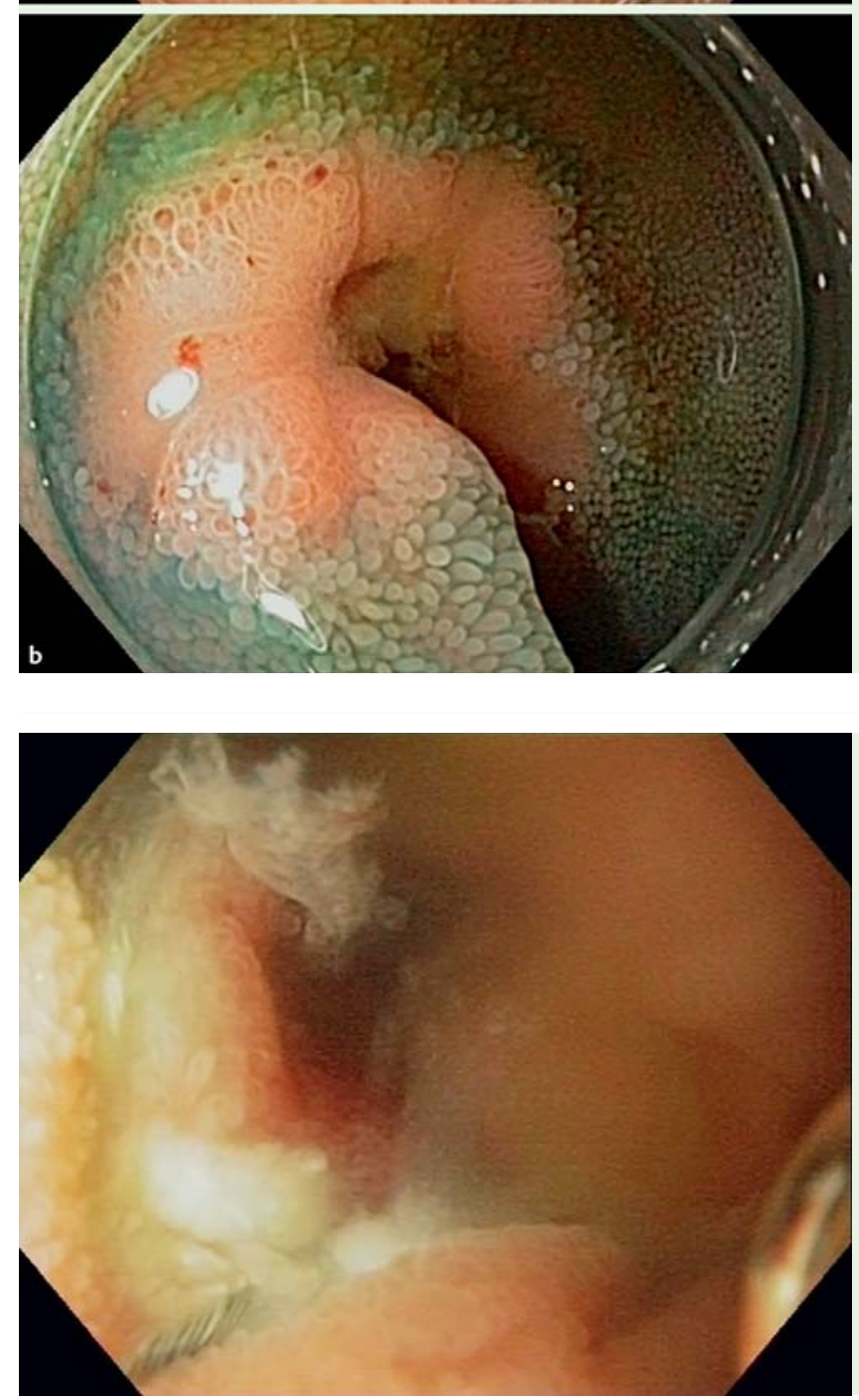

A 70-year-old man with Lynch syndrome underwent a subtotal colectomy and ileorectal anastomosis in 2005. During endoscopic follow-up, a large $(2.5 \mathrm{~cm})$, flat polyp was detected in the ileum, $20 \mathrm{~cm}$ proximal to the ileorectal anastomosis (৫ Fig. 1). Multiple biopsies were taken from the center of the polyp, which revealed adenoma with low grade dysplasia. The patient was referred for an attempt to remove the polyp endoscopically.

The lesion passed over one fold in the ileum and was judged to be difficult to remove safely using conventional endoscopic mucosal resection (EMR). Recently, underwater EMR without submucosal injection has been described, in which polyps are completely immersed in water and removed using a snare $[1,2]$. Underwater EMR has been reported to be a safe method of removing large, sessile, colorectal polyps [1] and laterally spreading duodenal polyps [2]. Thus, it was decided to use underwater EMR to remove this large, flat adenoma in the ileum.

The polyp was completely immersed in water, and a polypectomy snare $(13 \mathrm{~mm}$, Captivator; Boston Scientific, Natick, Massachusetts, USA) was used to resect it using a piecemeal technique ( $\bullet$ Fig.2). The lesion was completely removed without any bleeding, and there were no signs of perforation in the remaining wound ( $\bullet$ Fig.3). However, the patient presented with minor rectal bleeding the day after the procedure. Bleeding was easily managed endoscopically using coagulation forceps, after which the patient was discharged.

Large, flat adenomas in the small intestine are difficult to remove and are associated with a high risk of complications $[3,4]$. The present case is the first one in the literature describing the use of underwater EMR to remove a polyp in the ileum. In experienced hands, underwater EMR seems to be an effective method for removing polyps in difficult locations in the small intestine.

Endoscopy_UCTN_Code_TTT_1AP_2AD

Competing interests: None 


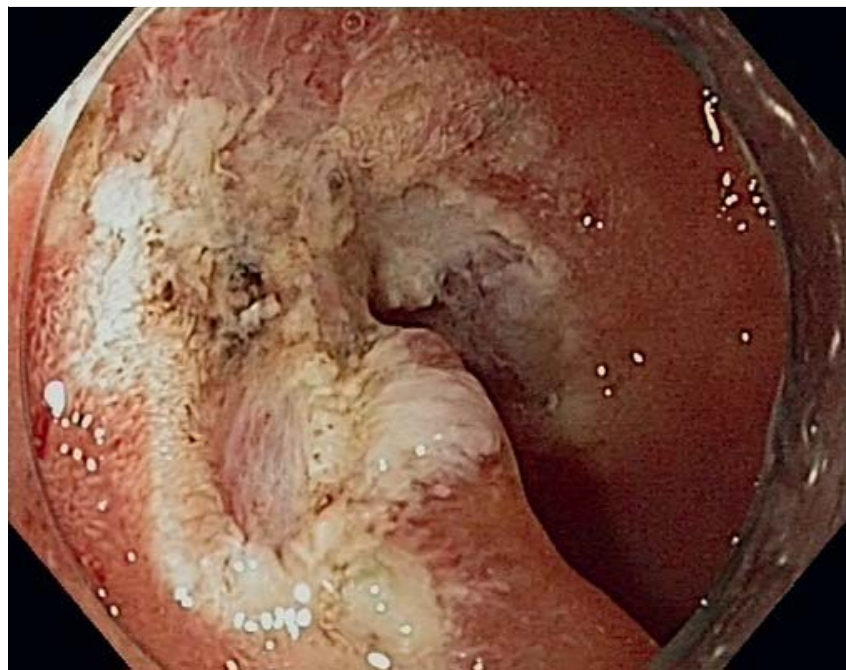

Fig.3 Endoscopic photograph showing the wound after underwater endoscopic mucosal resection.

\section{Noriya Uedo ${ }^{1}$, Artur Nemeth ${ }^{2}$, Ervin Toth ${ }^{2}$, Henrik Thorlacius ${ }^{3}$}

${ }^{1}$ Department of Gastrointestinal Oncology, Osaka Medical Center for Cancer and Cardiovascular Diseases, Osaka, Japan

2 Department of Clinical Sciences, Section of Endoscopy, Malmö, Skåne University Hospital, Lund University, Malmö, Sweden

${ }^{3}$ Department of Clinical Sciences, Section of Surgery, Malmö, Skåne University Hospital, Lund University, Malmö, Sweden

\section{References}

1 Binmoeller KF, Weilert F, Shah J et al. "Underwater" EMR without submucosal injection for large sessile colorectal polyps (with video). Gastrointest Endosc 2012; 75: $1086-$ 1091

2 Binmoeller KF, Shah JN, Bhat YM et al. "Underwater" EMR of sporadic laterally spreading nonampullary duodenal adenomas (with video). Gastrointest Endosc 2013; 78 : 496-502

3 Bourke MJ. Endoscopic resection in the duodenum: current limitations and future directions. Endoscopy 2013; 45: 127-132

4 Inoue $T$, Uedo $N$, Yamashina $T$ et al. Delayed perforation: a hazardous complication of endoscopic resection for non-ampullary duodenal neoplasm. Dig Endosc 2014; 26: $220-227$
Bibliography

Dol http://dx.doi.org/ 10.1055/s-0034-1377280

Endoscopy 2014; 46: E336-E337

(c) Georg Thieme Verlag KG

Stuttgart · New York

ISSN 0013-726X

Corresponding author Henrik Thorlacius, MD, PhD

Department of Clinical Sciences Section of Surgery

Skåne University Hospital

Lund University

20502 Malmö

Sweden

Fax: +46-40-336207

henrik.thorlacius@med.lu.se 